\title{
SIFAT FISIS DAN MEKANIS EMPAT JENIS KAYU ANDALAN ASAL SUMATERA UTARA
}

\section{(Physical and Mechanical Properties of Four Endemic Wood Species from North Sumatra)}

Oleh / By :

\author{
Gunawan Pasaribu
}

\begin{abstract}
This paper presents scientific information about physical and mechanical properties of four endemic wood species originated from North Sumatra. They consist of salagundi (Rhoudolia teysmanii), raru (Cotylelobium melanoxylon), mobe (Arthocarpus dadah) and medang landit (Persea rimosa). The properties which were examined covered wood density, moisture content, linear shrinkage (longitudinal, radial, and tangential directions), volumetric shrinkage, modulus of rupture (MOR), modulus of elasticity (MOE), compression strength and tensile strength. The experiment was carried out at Laboratory of Forest Product Processing and Utilization in the Research and Development Institute for Forestry (North Sumatra). The samples of wood materials were collected from Simalungun and Central Tapanuli, which lasted from June until December 2005. The results revealed that there were significant variations in the wood properties among those four endemic species, including the specific gravity, as follows: 0.44-0.54 (for medang landit), 0.55-0.69 (mobe), 0.80-0.86 (salagundi) and 1.02-1.09 (raru). The specific gravity of wood was linearly and positively correlated with particular mechanicalproperties, e.g. MOR and MOE.
\end{abstract}

Keyword: Endemic woodspecies, physical, mechanical and North Sumatra

\begin{abstract}
ABSTRAK
Tulisan ini menyajikan informasi ilmiah sifat fisis dan mekanis empat jenis kayu yaitu salagundi (Rhoudolia teysmaniz), raru (Cotylelobium melanoxylon), mobe (Arthocarpus dadah), dan medang landit (Persea rimosa). Sifat-sifat kayu yang diukur adalah berat jenis, kadar air, penyusutan linear (arah longitudinal, radial,tangensial), penyusutan volume, modulus patah (MOR), modulus elastisitas (MOE), keteguhan tekan dan keteguhan tarik sejajar serat. Penelitian dilaksanakan pada bulan Juni sampai Desember 2005 di Laboratorium Pengolahan dan Pemanfaatan Hasil Hutan, Balai Litbang Kehutanan Sumatera. Kayu diambil dari Kabupaten Simalungun dan Tapanuli Tengah. Hasil penelitian menunjukkan bahwa berat jenis kayu berturut-turut : 0.44-0.54 (medang landit), 0.55-0.69 (mobe), 0.80-0.86 (salagundi) dan 1.021.09 (raru). Nilai berat jenis berbanding lurus dan berkorelasi positif dengan sifat lainnya terutama sifat mekanis seperti MOR dan MOE.
\end{abstract}

Kata kunci: Jenis kayu andalan, fisis, mekanis dan Sumatera Utara. 


\section{PENDAHULUAN}

\section{A. Latar Belakang}

Di Indonesia sudah dikenal 400 jenis kayu yang dianggap penting, 267 diantaranya dikenal dalam perdagangan dan 133 digolongkan dalam kelompok kayu kurang dikenal. Saat ini umumnya pemanfaatan kayu kurang dikenal belum disesuaikan dengan sifatnya. Hal ini disebabkan karena data sifat dasar kayunya belum lengkap. Akibatnya nilai tambah yang diperoleh masih rendah. Demikian pula tarif Iuran Hasil Hutan (IHH) jenis ini dikelompokkan dalam kayu rimba campuran dengan tarif paling rendah sehingga pendapatan negara dari IHH belum maksimal.

Di sisi lain, jenis-jenis kayu perdagangan sudah semakin berkurang jumlahnya sehingga diperlukan substitusi dari jenis kayu kurang dikenal. Penggunaan kayu kurang dikenal diharapkan mampu sebagai pemasok dan penghara bahan baku industri perkayuan. Upaya ini dimaksudkan mampu meningkatkan diversifikasi jenis, menghemat penggunaan jenis kayu tertentu dan menjamin pasaran kayu bagi pengguna.

Untuk mendapatkan dan melengkapi data sifat dasar berbagai jenis kayu kurang dikenal, telah dilakukan penelitian sifat dasar dan penentuan penggunaannya yang tepat sehingga pemanfaatannya dapat lebih optimal agar dapat mewujudkan pembangunan hutan lestari.

\section{BAHAN DAN METODE}

\section{A. Bahan dan Alat}

Bahan penelitian adalah empat jenis kayu yaitu salagundi (Roudholia teysmanii), raru (Cotylelobium melanoxylon), mobe (Arthocarpus dadah) dan medang landit (Persea rimosa).

Peralatan yang diperlukan antara lain alat tulis, perlengkapan lapangan, chainsaw, gergaji, kaliper, oven, timbangan, alat uji mekanis dan kamera foto.

\section{B. Lokasi Penelitian}

Lokasi penelitian adalah Laboratorium Pengolahan dan Pemanfaatan Hasil Hutan, Balai Penelitian dan Pengembangan Kehutanan Sumatera dan Laboratorium Keteknikan Kayu, Fakultas Kehutanan, IPB. Contoh kayu diambil dari Kabupaten Simalungun dan Tapanuli Tengah, Propinsi Sumatera Utara.

\section{Metode Penelitian}

\section{Pengambilan bahan penelitian}

Setiap jenis kayu diambil dua pohon. Dicatat tinggi bebas cabang, tinggi total dan diameternya. Tempat tumbuh pohon, deskripsi pohon, fenotipe, sampel daun, biji, buah untuk herbarium dan informasi lainnya dikumpulkan sebagai data sekunder. Kemudian pohon ditebang dan dilakukan pembagian batang dengan membagi tiga bagian utama yaitu bagian pangkal, tengah dan ujung. Sisa dari lempengan sampel bagian pangkal, tengah dan ujung tersebut dijadikan bentuk sortimen papan dengan ketebalan $10 \mathrm{~cm}$. Potongan pangkal, 
tengah dan ujung pohon dimasukkan dalam plastik untuk menjaga kondisi kesegaran kayu (kayu tetap dalam kondisi basah).

\section{Pembuatan contoh uji dan pengujian}

Sortimen kayu berbentuk papan disimpan dalam ruangan secara teratur dan dibiarkan hingga mencapai kadar air kering udara. Setiap sortimen diserut kedua permukaan lebarnya sebelum dilakukan pembuatan contoh uji mekanis. Pengambilan dan pembuatan contoh uji fisis dan mekanis dilakukan menurut prosedur yang dilakukan oleh Kartasudirdja, 1987.

Contoh uji sifat fisis (kadar air, berat jenis dan perubahan dimensi) diperoleh dari lempengan pangkal, tengah dan ujung batang.

\section{a. Pengujian sifat fisis}

1) Penentuan kadar air kayu

Kadar air kayu ditentukan dengan menggunakan kaidah yang disusun oleh Karnasudirdja (1987). Contoh uji berukuran 2 × 2 × $2 \mathrm{~cm}$ ditimbang lalu dioven pada suhu $103+2^{\circ} \mathrm{C}$ hingga beratnya konstan. Setelah mencapai berat yang konstan maka contoh ditimbang lagi. Kadar air (KA) kayu kemudian dihitung berdasarkan rumus :

$$
\mathrm{KA}=\frac{\text { Berat basah }- \text { Berat kering }}{\text { Berat kering }} \times 100 \%
$$

2) Penentuan berat jenis kayu

Penentuan berat jenis ini didasarkan pada kaidah yang disusun oleh Karnasudirdja (1987). Contoh uji berukuran $2 \times 2 \times 2 \mathrm{~cm}$ dikeringkan dalam oven pada suhu $103+2^{\circ}$ Celcius hingga beratnya konstan. Setelah konstan contoh uji dilapisi dengan parafin dengan cara dicelupkan ke dalam parafin cair. Contoh uji kemudian diukur volumenya dengan menggunakan gelas ukur. Berat jenis (BJ) kayu kemudian ditentukan dengan rumus :

$$
\begin{gathered}
\mathrm{BJ}=\left|\frac{\text { Berat kering }}{\text { Volume kering }} \times 100 \%\right| / \text { kerapatan air } \\
\text { Catatan: kerapatan air dianggap } 1 \mathrm{gram} / \mathrm{cm}^{3}
\end{gathered}
$$

3) Penyusutan kayu

Penyusutan yang diukur meliputi penyusutan volumetrik, radial, tangensial dan longitudinal. Pada ketiga bagian kayu diukur dimensinya dan diberi tanda, agar dalam proses pengukuran berikutnya dilakukan pada posisi yang sama. Untuk penentuan persen penyusutan kayu, contoh uji kayu basah dengan ukuran $2 \times 2 \times 5 \mathrm{~cm}$ kemudian ditentukan volumenya. Contoh tersebut kemudian dioven hingga beratnya konstan dan kemudian contoh kering tersebut ditentukan kembali volumenya. Penyusutan untuk tiap bidang kayu dihitung berdasarkan rumus :

\section{b. Pengujian sifat mekanis}

$$
\text { Penyusutan }=\frac{\text { Dimensi basah }- \text { Dimensi kering }}{\text { Dimensi basah }} \times 100 \%
$$


Sifat mekanis kayu yang diuji antara lain Modulus of Elasticity (MOE), Modulus of Rupture (MOR), keteguhan tekan sejajar serat dan keteguhan tekan tegak lurus serat dengan menggunakan sistem British. Dalam pengujian mekanis kayu digunakan mesin uji mekanis Universal Testing Machine.

\section{Analisis Data}

Data yang dikumpulkan meliputi data sekunder dan data primer. Data sekunder berupa data studi literatur dan wawancara dengan instansi terkait. Rancangan percobaan dilakukan dengan rancangan faktorial dalam rancangan acak lengkap (RAL) dengan 3 ulangan. Tiap jenis dianalisis pengaruhnya posisi dalam batang (pangkal, tengah dan ujung) terhadap sifat fisis dan mekanis kayu (dimana ini dianggap sebagai faktor/perlakuan dalam RAL tersebut). Data-data tersebut ditabulasi dan dianalisa secara statistik dengan bantuan paket program Minitab.

\section{HASIL DAN PEMBAHASAN}

Hasil pengujian sifat fisis berupa berat jenis, kadar air dan penyusutan kayu (volumetrik, longitudinal, tangensial dan radial) dan sifat mekanis berupa MOR, MOE keteguhan tekan sejajar serat dan keteguhan tekan tegak lurus serat akan ditunjukkan pada Tabel 1, 2, 3 dan 4. Pengujian sifat mekanis kayu dilakukan pada kondisi kayu kering udara dengan kadar air sekitar $15 \%$.

\section{A. Salagundi (Roudbolia teysmanii)}

Kayu Salagundi oleh masyarakat sering digunakan untuk tiang pancang rumah. Bentuk pohon dan pancang yang lurus dari jenis ini, menjadikan sering dieksploitasi dalam bentuk tiang.

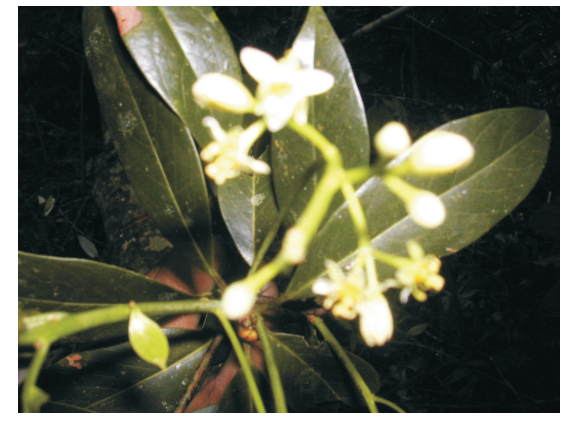

a. Daun dan Bunga (Leaves and flower)

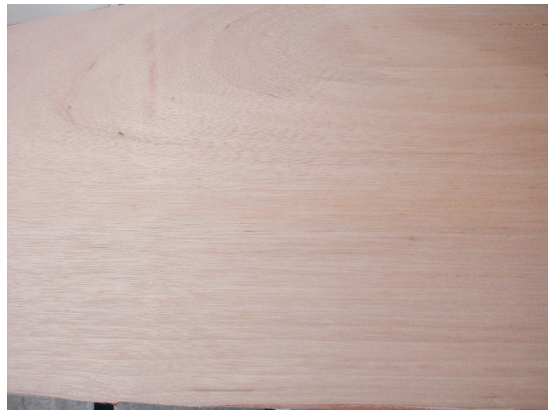

b. Kayu (Wood)

Gambar1. Profil daun/bunga (a) dankayu (b) jenis pohon salagundi Figure 1. Characteristics profile of leaves/flowers (a) and wood (b) from salagundi tree species 
Pohon salagundi memiliki tinggi mencapai 13 meter dengan tinggi batang bebas cabang 9 m sedangkan diameter berkisar 36 - $45 \mathrm{~cm}$. Pohon ini tidak memiliki banir apabila ada, ukurannya sangat kecil berupa bagian batang pohon yang menonjol. Tajuk pohon berupa tajung payung dengan percabangan yang jarang. Daun berbentuk ellips (Gambar 1.a) berkelompok pada bagian ranting. Kulit pohon beralur pendek, berwarna coklat dan terdapat bagian yang putih, tebal kulit berkisar 0,6-0,8 cm. Kulit sangat mudah dipisahkan dengan bagian batang pohon dan terdapat kambium yang sangat licin.

Warna kayu coklat kemerahan (Gambar 1.b) pada bagian gubal dan gelap (coklat tua) pada bagian kayu teras. Antara kayu gubal dan kayu teras terdapat perbedaan warna yang sangat kontras. Tekstur kayu halus dengan arah serat yang lurus.

Tabel1. Variasi sifat fisis dan mekanis kayu salagundi, akibat perbedaan pohon dan perbedaan tingkat ketinggian pada batang pohon

Table 1. Variations in physical and mechanical properties of salagundi wood due to different trees and different beight levels on the tree trunks

\begin{tabular}{|c|c|c|c|c|c|c|}
\hline \multirow{2}{*}{ No } & \multirow{2}{*}{$\begin{array}{l}\text { Sifat yang diamati } \\
\text { (Properties as observed) }\end{array}$} & \multicolumn{2}{|c|}{$\begin{array}{l}\text { Pohon } \\
(\text { Trees })^{1)}\end{array}$} & \multicolumn{3}{|c|}{$\begin{array}{l}\text { Lokasi ketinggian pada batang pohon } \\
\text { (Height locations on tree trunk.) }{ }^{2)}\end{array}$} \\
\hline & & 1 & 2 & $\begin{array}{l}\text { Pangkal } \\
\text { (Bottom) }\end{array}$ & $\begin{array}{l}\text { Tengah } \\
\text { (Center) }\end{array}$ & $\begin{array}{l}\text { Ujung } \\
\text { (Top) }\end{array}$ \\
\hline 1 & $\begin{array}{l}\text { Kadar air } \\
\text { (Moisture content), \% }\end{array}$ & $\begin{array}{l}80.9 \\
\text { (a) } 3)\end{array}$ & $\begin{array}{r}70.8 \\
\text { (b) }\end{array}$ & $\begin{array}{r}70.6 \\
\text { (a) }\end{array}$ & $\begin{array}{r}79.4 \\
\text { (b) }\end{array}$ & $\begin{array}{r}77.6 \\
\text { (b) }\end{array}$ \\
\hline 2 & $\begin{array}{l}\text { Berat jenis } \\
\text { (Specific gravity) }\end{array}$ & $\begin{array}{r}0.79 \\
\text { (a) }\end{array}$ & $\begin{array}{r}0.86 \\
\text { (b) }\end{array}$ & $\begin{array}{r}0.86 \\
\text { (a) }\end{array}$ & $\begin{array}{r}0.80 \\
\text { (b) }\end{array}$ & $\begin{array}{l}0.83 \\
(\mathrm{ab})\end{array}$ \\
\hline 3 & $\begin{array}{l}\text { Penyusutan volumetric } \\
\text { (Volumetric shrinkage), } \%\end{array}$ & $\begin{array}{r}16.62 \\
\text { (a) }\end{array}$ & $\begin{array}{r}16.54 \\
\text { (a) }\end{array}$ & $\begin{array}{r}16.87 \\
\text { (a) }\end{array}$ & $\begin{array}{r}15.42 \\
\text { (a) }\end{array}$ & $\begin{array}{r}17.44 \\
\text { (a) }\end{array}$ \\
\hline 4 & $\begin{array}{l}\text { Penyusutan longitudinal } \\
\text { (Longitudinal shrinkage), \% }\end{array}$ & $\begin{array}{r}0.31 \\
\text { (a) }\end{array}$ & $\begin{array}{r}0.93 \\
\text { (b) }\end{array}$ & $\begin{array}{r}0.40 \\
\text { (a) }\end{array}$ & $\begin{array}{r}0.90 \\
\text { (a) }\end{array}$ & $\begin{array}{r}0.55 \\
\text { (a) }\end{array}$ \\
\hline 5 & $\begin{array}{l}\text { Penyusutan tangensial (Tangential } \\
\text { shrinkage), } \%\end{array}$ & $\begin{array}{r}9.31 \\
\text { (a) }\end{array}$ & $\begin{array}{r}9.21 \\
\text { (a) }\end{array}$ & $\begin{array}{r}9.21 \\
\text { (a) }\end{array}$ & $\begin{array}{r}8.97 \\
\text { (a) }\end{array}$ & $\begin{array}{r}9.59 \\
\text { (a) }\end{array}$ \\
\hline 6 & $\begin{array}{l}\text { Penyusutan radial } \\
\text { (Radial shrinkage), \% }\end{array}$ & $\begin{array}{r}5.70 \\
\text { (a) }\end{array}$ & $\begin{array}{r}3.74 \\
\text { (b) }\end{array}$ & $\begin{array}{r}6.56 \\
\text { (a) }\end{array}$ & $\begin{array}{r}4.09 \\
\text { (b) }\end{array}$ & $\begin{array}{r}3.51 \\
\text { (b) }\end{array}$ \\
\hline 7 & $\begin{array}{l}\text { Modulus elastisitas } \\
\text { (Modulus of elasticity), } \mathrm{kg} / \mathrm{cm}^{2}\end{array}$ & $\begin{array}{r}118.044 \\
\text { (a) }\end{array}$ & $\begin{array}{r}171.159 \\
\text { (a) }\end{array}$ & $\begin{array}{r}178.447 \\
\text { (a) }\end{array}$ & $\begin{array}{r}128.423 \\
\text { (a) }\end{array}$ & $\begin{array}{r}126.935 \\
\text { (a) }\end{array}$ \\
\hline 8 & $\begin{array}{l}\text { Modulus patah } \\
\text { (Modulus of rupture), } \mathrm{kg} / \mathrm{cm}^{2}\end{array}$ & $\begin{array}{r}1.162 \\
\text { (a) }\end{array}$ & $\begin{array}{r}1.192 \\
\text { (a) }\end{array}$ & $\begin{array}{r}1.161 \\
\text { (a) }\end{array}$ & $\begin{array}{r}1.226 \\
\text { (a) }\end{array}$ & $\begin{array}{r}1.143 \\
\text { (a) }\end{array}$ \\
\hline 9 & $\begin{array}{l}\text { Keteguhan tekan } \\
\text { (Compression strength), } \mathrm{kg} / \mathrm{cm}^{2}\end{array}$ & $\begin{array}{r}576.1 \\
\text { (a) }\end{array}$ & $\begin{array}{r}627.2 \\
(\mathrm{~b}) \\
\end{array}$ & $\begin{array}{r}665.4 \\
\text { (a) }\end{array}$ & $\begin{array}{r}589.2 \\
(\mathrm{~b}) \\
\end{array}$ & $\begin{array}{r}550.3 \\
\text { (b) }\end{array}$ \\
\hline 10 & $\begin{array}{l}\text { Keteguhan tarik } \\
\text { (Tensile strength), } \mathrm{kg} / \mathrm{cm}^{2}\end{array}$ & $\begin{array}{r}1043 \\
\text { (a) }\end{array}$ & $\begin{array}{r}782 \\
\text { (a) }\end{array}$ & $\begin{array}{r}689 \\
\text { (a) }\end{array}$ & $\begin{array}{r}1155 \\
\text { (a) } \\
\end{array}$ & $\begin{array}{r}895 \\
\text { (a) }\end{array}$ \\
\hline
\end{tabular}

Keterangan (Remarks):

1) Untuk setiap pohon (nomor 1 atau 2), merupakan rata-rata dari tingkat ketinggian pada batang pohon (Foreach tree (number 1 or 2 ), revealing the average from three height levels of the tree trunk)

2) Untuk setiap tingkat ketinggian pada batang pohon (pangkal, tengah atau ujung), merupakan rata-rata dari 2 pohon (nomor 1 dan 2) (For each height level on the tree trunk, e.g. bottom, center and top parts, revealing the average from 2 trees (number 1 and 2 ))

3) Angka pada baris yang sama yang diikuti oleh huruf yang sama tidak berbeda nyata pada taraf $5 \%$ (Figures in the same row followed by similar (common) letters are not significantly different at $5 \%$ level: $a>b$ ) 
Hasil analisis sidik ragam fisis-mekanis kayu dapat dilihat pada Tabel 1. Kadar air kayu antar pohon dan antar posisi (pangkal, tengah, ujung) dalam pohon salagundi berbeda nyata, dimana kadar air pada pohon pertama lebih besar dari pohon yang kedua. Variasi kadar air dalam pohon menunjukkan bahwa kadar air dari bagian pangkal ke bagian tengah mengalami peningkatan dan menurun lagi pada bagian ujung.

Berat jenis kayu merupakan sifat penting dalam rangka peruntukan kayu. Dari nilai berat jenis juga dapat diduga sifat kekuatan kayunya. Berat jenis kedua pohon salagundi yang diteliti berbeda nyata, demikian juga dalam satu pohon menunjukkan penurunan dari bagian pangkal ke arah tengah dan meningkat lagi ke arah ujung pohon.

Menurut Haygreen dan Bowyer (1989), penyusutan tangensial kayu lebih besar 1,5 sampai 3 kali dibanding dengan kayu penyusutan radial dan penyusutan longitudinal memiliki nilai yang paling kecil. Pada kedua pohon salagundi, memiliki penyusutan longitudinal yang berbeda. Demikian pula pada penyusutan radial antar pohon dan antar posisi dalam satu pohon juga berbeda. Persen penyusutan menurun dari pangkal ke bagian tengah dan ke bagian ujung pohon. Nilai berat jenis dan penyusutan volume berkorelasi positif dengan nilai koefisien korelasi sebesar 0,001.

Nilai MOE, MOR dan tarik sejajar serat tidak berbeda nyata antar pohon dan dalam pohon itu sendiri. Nilai berat jenis terhadap MOE dan MOR berkorelasi positif dengan nilai koefisien korelasi masing-masing sebesar 0,16 dan 0,02. Akan tetapi, keteguhan tekan sejajar serat memiliki perbedaan antar pohon dan dalam satu pohon dimana nilainya cenderung menurun dari pangkal ke arah tengah dan ujung. Dari nilai MOE dan MOR contoh uji, kayu Salagundi digolongkan ke dalam kelas kuat I. Kayunya keras dengan berat jenis yang termasuk kelas tinggi sehingga jenis ini cocok untuk produksi bahan baku yang memerlukan kekuatan. Seratnya lurus dan halus, cocok untuk kusen indah dan mebel-mebel yang menampilkan serat indah.

\section{B. Raru (Cotylelobium melanoxylon)}

Pohon raru yang tumbuh alami di wilayah Tapanuli, sangat sulit dijumpai dengan diameter besar. Tekanan masyarakat terhadap pohon ini sangat tinggi. Pohon raru berdiameter $10 \mathrm{~cm}$ sudah banyak dikuliti untuk dijual ke pasar. Kulit raru diyakini masyarakat mampu menambah cita rasa dan kadar alkohol dari minuman tuak (minuman tradisional dari aren). Berdasarkan kajian ilmiah, kulit kayu ini mengandung kadar tanin yang cukup tinggi, yang cocok digunakan sebagai bahan pengawet alami pada makanan. Pohon raru hanya dapat dijumpai di lokasi yang jauh dalam hutan yang sudah sulit dijangkau masyarakat. Kayunya ditinggal berdiri, padahal kayu ini mempunyai kekuatan yang tinggi (Heyne, 1987).

Pohon raru tingginya mencapai 25 meter dengan tinggi batang bebas cabang $15 \mathrm{~m}$ sedangkan diameter berkisar 30-50 cm. Pohon memiliki banir dengan percabangan yang jarang. Daun berbentuk ellips (Gambar 2.a) berkelompok pada bagian ranting. Kulit pohonnya beralur pendek yang berwarna putih kehijauan. Tebal kulit berkisar 0,6 - 1,0 cm. Kulit mudah dipisahkan dari bagian batang.

Warna kayu (Gambar 2.b) kuning kecoklatan. Antara kayu gubal dan kayu teras tidak terdapat perbedaan warna yang jelas. Tekstur kayu halus dengan arah serat yang lurus dan indah. 
Tabe12. Variasi sifat fisis dan mekanis kayu raru, akibat perbedaan pohon dan perbedaan tingkat ketinggian pada batang pohon

Table 2. Variations in physical and mechanical properties of raru wood, due to different trees and different beight levels on the tree trunks

\begin{tabular}{|c|c|c|c|c|c|c|}
\hline \multirow{2}{*}{ No } & \multirow{2}{*}{$\begin{array}{l}\text { Sifat yang diamati } \\
\text { (Properties as observed / examined) }\end{array}$} & \multicolumn{2}{|c|}{$\begin{array}{l}\text { Pohon } \\
(\text { Trees) })^{1)}\end{array}$} & \multicolumn{3}{|c|}{$\begin{array}{c}\text { Lokasi ketinggian pada batang pohon } \\
\text { (Height locations on tree trunk.) }{ }^{2)}\end{array}$} \\
\hline & & 1 & 2 & $\begin{array}{l}\text { Pangkal } \\
\text { (Bottom) }\end{array}$ & $\begin{array}{l}\text { Tengah } \\
\text { (Center) }\end{array}$ & $\begin{array}{l}\text { Ujung } \\
\text { (Top) }\end{array}$ \\
\hline 1 & $\begin{array}{l}\text { Kadar air } \\
\text { (Moisture content), \% }\end{array}$ & $\begin{array}{l}38.6 \\
\text { (a) } 3)\end{array}$ & $\begin{array}{r}38.5 \\
\text { (a) }\end{array}$ & $\begin{array}{r}35.1 \\
\text { (a) }\end{array}$ & $\begin{array}{r}41.0 \\
\text { (a) }\end{array}$ & $\begin{array}{r}39.7 \\
\text { (a) }\end{array}$ \\
\hline 2 & $\begin{array}{l}\text { Berat jenis } \\
\text { (Specific gravity) }\end{array}$ & $\begin{array}{r}1.08 \\
\text { (a) }\end{array}$ & $\begin{array}{r}1.01 \\
\text { (a) }\end{array}$ & $\begin{array}{r}1.09 \\
\text { (a) }\end{array}$ & $\begin{array}{r}1.03 \\
\text { (a) }\end{array}$ & $\begin{array}{r}1.02 \\
\text { (a) }\end{array}$ \\
\hline 3 & $\begin{array}{l}\text { Penyusutan volumetric } \\
\text { (Volumetric shrinkage), \% }\end{array}$ & $\begin{array}{r}16.41 \\
\text { (a) }\end{array}$ & $\begin{array}{r}12.57 \\
\text { (a) }\end{array}$ & $\begin{array}{r}13.2 \\
\text { (a) }\end{array}$ & $\begin{array}{r}13.3 \\
\text { (a) }\end{array}$ & $\begin{array}{r}17.0 \\
\text { (a) }\end{array}$ \\
\hline 4 & $\begin{array}{l}\text { Penyusutan longitudinal } \\
\text { (Longitudinal shrinkage), \% }\end{array}$ & $\begin{array}{r}0.60 \\
\text { (a) }\end{array}$ & $\begin{array}{r}0.59 \\
\text { (a) }\end{array}$ & $\begin{array}{r}0.60 \\
\text { (a) }\end{array}$ & $\begin{array}{r}0.71 \\
\text { (a) }\end{array}$ & $\begin{array}{r}0.46 \\
\text { (a) }\end{array}$ \\
\hline 5 & $\begin{array}{l}\text { Penyusutan tangensial (Tangential } \\
\text { shrinkage), } \%\end{array}$ & $\begin{array}{r}9.68 \\
\text { (a) }\end{array}$ & $\begin{array}{r}7.56 \\
\text { (a) }\end{array}$ & $\begin{array}{r}7.27 \\
\text { (a) }\end{array}$ & $\begin{array}{r}7.74 \\
\text { (a) }\end{array}$ & $\begin{array}{r}10.86 \\
\text { (a) }\end{array}$ \\
\hline 6 & $\begin{array}{l}\text { Penyusutan radial } \\
\text { (Radial shrinkage), \% }\end{array}$ & $\begin{array}{r}6.93 \\
\text { (a) }\end{array}$ & $\begin{array}{r}4.86 \\
\text { (a) }\end{array}$ & $\begin{array}{r}5.81 \\
\text { (a) }\end{array}$ & $\begin{array}{r}5.34 \\
\text { (a) }\end{array}$ & $\begin{array}{r}6.53 \\
\text { (a) }\end{array}$ \\
\hline 7 & $\begin{array}{l}\text { Modulus elastisitas } \\
\text { (Modulus of elasticity), } \mathrm{kg} / \mathrm{cm}^{2}\end{array}$ & $\begin{array}{r}157.739 \\
\text { (a) }\end{array}$ & 158.390 (a) & $\begin{array}{r}149.842 \\
\text { (a) }\end{array}$ & $\begin{array}{r}165.829 \\
\text { (a) }\end{array}$ & $\begin{array}{r}158.522 \\
\text { (a) }\end{array}$ \\
\hline 8 & $\begin{array}{l}\text { Modulus patah } \\
\text { (Modulus of rupture), } \mathrm{kg} / \mathrm{cm}^{2}\end{array}$ & $\begin{array}{r}1.554 \\
\text { (a) }\end{array}$ & $\begin{array}{r}1.548 \\
\text { (a) }\end{array}$ & $\begin{array}{r}1.630 \\
\text { (a) }\end{array}$ & $\begin{array}{r}1.441 \\
\text { (a) }\end{array}$ & $\begin{array}{r}1.583 \\
\text { (a) }\end{array}$ \\
\hline 9 & $\begin{array}{l}\text { Keteguhan tekan } \\
\text { (Compression strength), } \mathrm{kg} / \mathrm{cm}^{2}\end{array}$ & $\begin{array}{r}708 \\
\text { (a) }\end{array}$ & $\begin{array}{r}762 \\
\text { (a) }\end{array}$ & $\begin{array}{r}705 \\
\text { (a) }\end{array}$ & $\begin{array}{r}748 \\
\text { (a) }\end{array}$ & $\begin{array}{r}752 \\
\text { (a) }\end{array}$ \\
\hline 10 & $\begin{array}{l}\text { Keteguhan tarik } \\
\text { (Tensile strength), } \mathrm{kg} / \mathrm{cm}^{2}\end{array}$ & $\begin{array}{r}1531 \\
\text { (a) }\end{array}$ & $\begin{array}{r}1230 \\
\text { (a) }\end{array}$ & $\begin{array}{r}1282 \\
\text { (a) }\end{array}$ & $\begin{array}{r}1603 \\
\text { (a) }\end{array}$ & $\begin{array}{r}1257 \\
\text { (a) }\end{array}$ \\
\hline
\end{tabular}

Keterangan (Remarks):

1) Untuk setiap pohon (nomor 1 atau 2), merupakan rata-rata dari tingkat ketinggian pada batang pohon (Foreach tree (number 1 or 2), revealing the average from three height levels of the tree trunk)

2) Untuk setiap tingkat ketinggian pada batang pohon (pangkal, tengah atau ujung), merupakan rata-rata dari 2 pohon (nomor 1 dan 2) (For each height level on the tree trunk, e.g. bottom, center and top/ upperparts revealing the average from 2 trees (number 1 and 2 ))

3) Angka pada baris yang sama yang diikuti oleh huruf yang sama tidak berbeda nyata pada taraf $5 \%$ (Figures in the same row followed by similar (common) letters are not significantly different at $5 \%$ level: $a>b$ )

Tabel 2 menunjukkan adanya perbedaan sifat fisis dan mekanis kayu raru. Dari analisis sidik ragam yang dilakukan terhadap semua parameter fisis-mekanis kayu tidak ditemukan perbedaan sifat yang nyata antar pohon dan antar posisi dalam pohon itu sendiri. Nilai berat jenis dan penyusutan volume berkorelasi positif dengan nilai koefisien korelasi sebesar 0,005.

Berat jenis kayu mencapai 1,02 - 1,09, jenis ini cocok digunakan untuk konstruksi berat misalnya tiang listrik, perkapalan dan sebagainya. Dari nilai MOE dan MOR, kayu raru digolongkan ke dalam kelas kuat I. Nilai berat jenis terhadap MOE dan MOR berkorelasi positif dengan nilai koefisien korelasi masing-masing sebesar 0,047 dan 0,0006. Akan tetapi pada waktu kayu disimpan di laboratorium sangat cepat diserang oleh rayap kayu kering/bubuk kayu kering. Jenis ini potensial dikembangkan di masa depan sebagi jenis andalan setempat yang memiliki nilai ganda. 


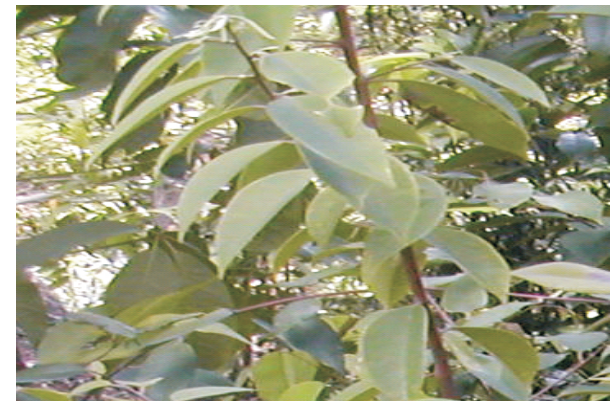

a. Daun (Leaf)

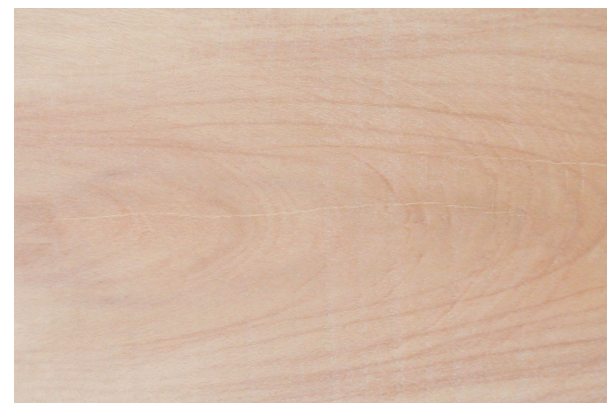

b. Kayu (Wood)

Gambar 2. Profil daun (a) dan kayu (b) jenis pohon raru

Figure 2. Characteristics profile of leaves (a) and wood (b) from raru tree species

\section{Mobe (Artocharpus dadab)}

Buah pohon mobe sangat dikenal oleh masyarakat Tapanuli, yang dimanfaatkan sebagai bumbu masakan arsik (pepes ikan ala Tapanuli). Selain itu dilaporkan juga bahwa getah pohon mobe digunakan sebagai obat pembersih luka kotor, daunnya untuk obat sakit perut terutama bagian pucuk. Kayu mobe memiliki serat sangat kasar.

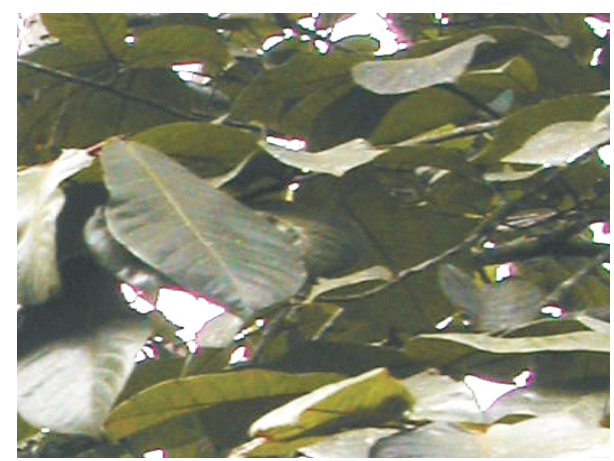

a. Daun (Leaf)

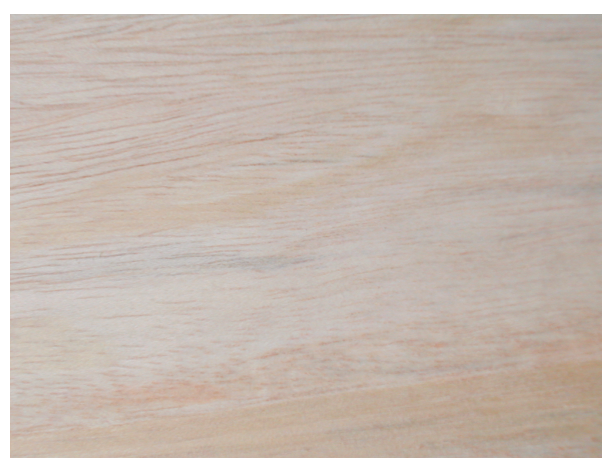

b. Kayu (Wood)

Gambar 3. Profil daun (a) dan kayu (b) jenis pohon mobe Figure 3. Characteristics profile of leaves (a) and wood (b) from mobe tree species 
Pohon mobe memiliki tinggi mencapai 40 - 60 meter dengan tinggi batang bebas cabang $20 \mathrm{~m}$ sedangkan diameter berkisar $150-300 \mathrm{~cm}$. Pohon ini tidak memiliki banir. Daun berbentuk ellips (Gambar 3.a) yang lebar. Kulit beralur dangkal, berwarna merah kecoklatan. Tebal kulit berkisar 0,9-1,3 cm. Pada saat kayu dibelah, serat tampak bergelombang mengakibatkan permukaan papan tidak halus.

Kayu (Gambar 3.b) berwarna kuning muda hampir merata dari bagian gubal dan teras sehingga antara gubal dan teras tidak terdapat perbedaan warna yang jelas. Tekstur kayu kasar dengan arah serat berpadu.

Tabel.3. Variasi sifat fisis dan mekanis kayu mobe, akibat perbedaan pohon dan perbedaan tingkat ketinggian pada batang pohon

Table 3. Variations in physical and mechanical properties of mobe wood, due to different trees and different height levels on the tree trunks

\begin{tabular}{|c|c|c|c|c|c|c|}
\hline \multirow{2}{*}{ No } & \multirow{2}{*}{$\begin{array}{l}\text { Sifat yang diamati } \\
\text { (Properties as observed) }\end{array}$} & \multicolumn{2}{|c|}{$\begin{array}{l}\text { Pohon } \\
(\text { Trees) })^{1)}\end{array}$} & \multicolumn{3}{|c|}{$\begin{array}{l}\text { Lokasi ketinggian pada batang pohon } \\
\text { (Height locations on tree trunk.) }{ }^{2)}\end{array}$} \\
\hline & & 1 & 2 & $\begin{array}{r}\text { Pangkal } \\
\text { (Bottom) }\end{array}$ & $\begin{array}{l}\text { Tengah } \\
\text { (Center) }\end{array}$ & $\begin{array}{l}\text { Ujung } \\
\text { (Top) }\end{array}$ \\
\hline \multirow[t]{2}{*}{1} & Kadar air & 70.7 & 82.6 & 83.3 & 84.1 & 62.6 \\
\hline & (Moisture content), $\%$ & (a) ${ }^{3)}$ & (a) & (a) & (a) & (a) \\
\hline \multirow[t]{2}{*}{2} & Berat jenis & 0.68 & 0.57 & 0.69 & 0.55 & 0.63 \\
\hline & (Specific gravity) & (a) & (b) & (a) & (b) & (ab) \\
\hline \multirow[t]{2}{*}{3} & Penyusutan volumetric & 10.9 & 12.0 & 11.3 & 12.5 & 10.6 \\
\hline & (Volumetric shrinkage), \% & (a) & (a) & (a) & (a) & (a) \\
\hline \multirow[t]{2}{*}{4} & Penyusutan longitudinal & 0.77 & 0.82 & 0.60 & 0.96 & 0.83 \\
\hline & (Longitudinal shrinkage), \% & (a) & (a) & (a) & (a) & (a) \\
\hline \multirow[t]{2}{*}{5} & Penyusutan tangensial & 6.76 & 7.72 & 6.73 & 7.95 & 7.06 \\
\hline & (Tangential shrinkage), $\%$ & (a) & (a) & (a) & (a) & (a) \\
\hline \multirow[t]{2}{*}{6} & Penyusutan radial & 3.67 & 3.91 & 4.31 & 3.99 & 3.07 \\
\hline & (Radial shrinkage), $\%$ & (a) & (a) & (a) & (a) & (a) \\
\hline \multirow[t]{2}{*}{7} & Modulus elastisitas & 106.288 & 86.944 & 117.254 & 93.887 & 78.707 \\
\hline & (Modulus of elasticity), $\mathrm{kg} / \mathrm{cm}^{2}$ & (a) & (b) & (a) & (b) & (b) \\
\hline \multirow[t]{2}{*}{8} & Modulus patah & 774 & 677 & 810 & 663 & 705 \\
\hline & (Modulus of rupture), $\mathrm{kg} / \mathrm{cm}^{2}$ & (a) & (a) & (a) & (b) & $(\mathrm{ab})$ \\
\hline \multirow[t]{2}{*}{9} & Keteguhan tekan & 311.6 & 372.4 & 404.4 & 348.7 & 273.0 \\
\hline & (Compression strength), $\mathrm{kg} / \mathrm{cm}^{2}$ & (a) & (b) & (a) & (b) & (c) \\
\hline \multirow[t]{2}{*}{10} & Keteguhan tarik & 868 & 846 & 999 & 687 & 885 \\
\hline & (Tensile strength), $\mathrm{kg} / \mathrm{cm}^{2}$ & (a) & (a) & (a) & (a) & (a) \\
\hline
\end{tabular}

Keterangan (Remarks):

1) Untuk setiap pohon (nomor 1 atau 2), merupakan rata-rata dari tingkat ketinggian pada batang pohon (Foreach tree (number 1 or 2 ), revealing the average from three height levels of the tree trunk)

2) Untuk setiap tingkat ketinggian pada batang pohon (pangkal, tengah atau ujung), merupakan ratarata dari 2 pohon (nomor 1 dan 2) (For each height level on the tree trunk, e.g. bottom, center and top/ upper parts revealing the average from 2 trees (number 1 and 2 ))

3) Angka pada baris yang sama yang diikuti oleh huruf yang sama tidak berbeda nyata pada taraf $5 \%$ (Figures in the same row followed by similar (common) letters are not significantly different at $5 \%$ level: $a>b$ ) 
Tabel 3 menunjukkan adanya perbedaan sifat fisis dan mekanis kayu mobe dari kedua pohon. Dari analisis sidik ragam yang dilakukan terhadap semua parameter fisis-mekanis kayu ditemukan beberapa perbedaan sifat yang nyata antar pohon dan antar posisi dalam pohon. Sifat fisis berupa berat jenis kayu antar pohon dan antar posisi dalam satu pohon terdapat perbedaan yang nyata. Berat jenis antar pohon berbeda dimana pohon kedua lebih kecil dari pohon pertama. Berat jenis menurun bagian pangkal lebih tinggi dari bagian tengah dan meningkat lagi di bagian ujung pohon. Nilai berat jenis dan penyusutan volume berkorelasi positif dengan nilai koefisien korelasi sebesar 0,14 .

Modulus elastisitas kayu mobe pohon pertama dan pohon kedua berbeda. Demikian juga antar posisi dalam satu pohon menunjukkan perbedaan, dimana bagian pangkal lebih besar dari pada bagian tengah demikian pula bagian ujung lebih kecil dari bagian tengah. Modulus patah antar posisi dalam pohon berbeda dimana terjadi penurunan dari pangkal ke bagian tengah dan meningkat lagi ke bagian ujung. Nilai berat jenis terhadap MOE dan MOR berkorelasi positif dengan nilai koefisien korelasi masing-masing sebesar 0,23 dan 0,50. Nilai keteguhan tarik sejajar serat tidak berbeda nyata sementara nilai keteguhan tekan sejajar serat menunjukkan perbedaan yang nyata baik antara pohon maupun dalam pohon itu sendiri. Pada bagian pangkal keteguhan tekan sejajar serat besar dan menurun ke arah tengah dan menurun lagi sampai bagian ujung pohon.

Berat jenis kayu mobe sekitar 0.55 - 0.69 sehingga masih dapat digunakan untuk keperluan konstruksi ringan, kusen dan perabotan yang tidak membutuhkan penampilan indah. Dari nilai MOE dan MOR contoh uji, kayu mobe digolongkan ke dalam kelas kuat IIIII. Jenis ini cocok diintrodusikan untuk program rehabilitasi karena berupa pohon multiguna yang mudah diterima oleh masyarakat.

\section{Medang Landit (Persea rimosa)}

Medang landit merupakan jenis pohon yang akhir-akhir ini dieksploitasi secara besarbesaran oleh masyarakat untuk diambil kulitnya. Kulit kayu medang oleh petani dijual seharga Rp 1.500,- per kilogram untuk bahan pembuat obat anti nyamuk.

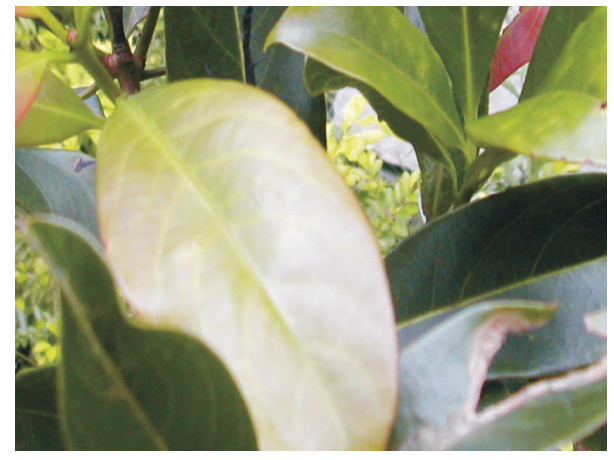

a. Daun (Leaf)

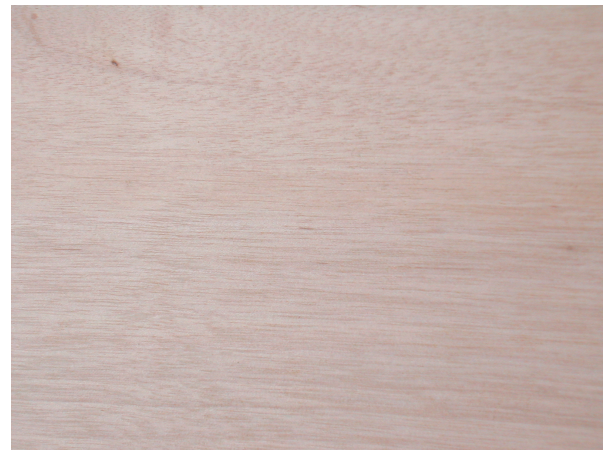

b. Kayu (Wood)

Gambar 4. Profil daun (a) dan kayu (b) jenis pohon medang landit

Figure 4. Characteristics profile of leaves (a) and wood (b) from medang landit tree species 
Pohon medang landit memiliki tinggi 45 meter dengan tinggi batang bebas cabang $10 \mathrm{~m}$ sedangkan diameter berkisar 37 - $45 \mathrm{~cm}$. Pohon tidak memiliki banir walaupun ada ukurannya sangat kecil berupa bagian batang pohon yang menonjol. Tajuk pohon berupa tajung payung dengan percabangan yang sedang. Daun berbentuk ellips menyebar, daun muda berwarna merah (Gambar 4.a). Kulit pohon beralur dangkal yang berwarna coklat dan banyak terdapat bagian yang putih tebal kulit berkisar 0,6 - 1,0 cm. Kulit sulit dipisahkan dengan bagian batang.

Kayu teras berwarna kuning tua sampai kemerahan yang sangat mudah dibedakan dengan bagian kayu gubal yang berwarna kuning agak putih (broken white). Antara kayu gubal dan kayu teras terdapat perbedaan warna yang jelas. Tekstur kayu halus dengan arah serat yang lurus.

Perbedaan sifat fisis dan mekanis kayu medang landit dapat dilihat pada Tabel 4. Dari analisis sidik ragam yang dilakukan terhadap semua parameter fisis-mekanis kayu ditemukan beberapa perbedaan sifat yang nyata antar pohon dan antar posisi dalam pohon. Berat jenis kayu dari bagian pangkal menurun sampai bagian tengah dan naik lagi pada ke bagian ujung. Penyusutan volumetrik, longitudinal dan radial tidak berbeda antar pohon dan dalam pohon itu sendiri, lain halnya dengan penyusutan tangensial terdapat perbedaan antar posisi dalam pohon. Nilai berat jenis dan penyusutan volume berkorelasi positif dengan nilai koefisien korelasi sebesar 0,22 .

Modulus elastisitas, keteguhan tekan sejajar serat dan keteguhan tarik sejajar serat tidak terdapat perbedaan yang nyata antar pohon dan antar posisi dalam pohon. Perbedaan terjadi pada modulus patah baik antar pohon dan antar posisi dalam pohon. Medang memiliki berat jenis sedang dan dari nilai MOE dan MOR, digolongkan ke dalam kelas kuat II. Nilai berat jenis terhadap MOE dan MOR berkorelasi positif dengan nilai koefisien korelasi masingmasing sebesar 0,0006 dan 0,01. Kayunya memiliki penampilan dan warna kayu yang menarik, cocok dimanfaatkan untuk produksi alat rumah tangga, mebel dan untuk konstruksi ringan.

\section{KESIMPULAN DAN SARAN}

1. Berat jenis kayu berturut-turut: Medanglandit (Persea rimosa), 0.44-0.54; Mobe (Arthocarpus dadab), 0.55-0.69, Salagundi (Roudholia teysmanii), 0.80-0.86 dan Raru (Cotylelobium melanoxylon), 1.02-1.09.

2. Terdapat korelasi positif antara berat jenis dengan sifat fisis (penyusutan) dan dengan sifat mekanis kayu (MOE dan MOE) dari keempat jenis kayu yang diteliti.

3. Kelas kuat (KK) kayu berturut-turut : Medang landit (Persea rimosa), KK. II; Mobe (Arthocarpus dadah), KK. II-III, Salagundi (Roudholia teysmanii), KK. I dan Raru (Cotylelobium melanoxylon), KK. I.

4. Disarankan agar jenis-jenis yang memiliki manfaat ganda dan sifat dasar yang dapat dipergunakan untuk berbagai macam keperluan tersebut agar dikembangkan di hutan rakyat maupun pilihan untuk jenis tanaman reboisasi. 
Tabel 4. Variasi sifat fisis dan mekanis kayu medanglandit, akibat perbedaan pohon dan perbedaan tingkat ketinggian pada batang pohon

Table 4. Variations in physical and mechanical properties of medang landit wood, due to different trees and different beight levels on the tree trunks

\begin{tabular}{|c|c|c|c|c|c|c|}
\hline \multirow{2}{*}{ No } & \multirow{2}{*}{$\begin{array}{l}\text { Sifat yang diamati } \\
\text { (Properties as observed) }\end{array}$} & \multicolumn{2}{|c|}{$\begin{array}{l}\text { Pohon } \\
(\text { Trees) })^{1)}\end{array}$} & \multicolumn{3}{|c|}{$\begin{array}{c}\text { Lokasi ketinggian pada batang pohon } \\
\text { (Height locations on tree trunk) }{ }^{2)}\end{array}$} \\
\hline & & 1 & 2 & $\begin{array}{l}\text { Pangkal } \\
\text { (Bottom) }\end{array}$ & $\begin{array}{l}\text { Tengah } \\
\text { (Center) }\end{array}$ & $\begin{array}{l}\text { Ujung } \\
\text { (Top) }\end{array}$ \\
\hline 1 & $\begin{array}{l}\text { Kadar air } \\
\text { (Moisture content), } \%\end{array}$ & $\begin{array}{l}89.6 \\
\text { (a) } 3)\end{array}$ & $\begin{array}{r}84.7 \\
\text { (a) }\end{array}$ & $\begin{array}{r}81.5 \\
\text { (a) }\end{array}$ & $\begin{array}{r}78.7 \\
\text { (a) }\end{array}$ & $\begin{array}{r}101.2 \\
\text { (b) }\end{array}$ \\
\hline 2 & $\begin{array}{l}\text { Berat jenis } \\
\text { (Specific gravity) }\end{array}$ & $\begin{array}{r}0.51 \\
\text { (a) }\end{array}$ & $\begin{array}{r}0.51 \\
\text { (b) }\end{array}$ & $\begin{array}{r}0.54 \\
\text { (a) }\end{array}$ & $\begin{array}{r}0.44 \\
\text { (b) }\end{array}$ & $\begin{array}{r}0.54 \\
\text { (a) }\end{array}$ \\
\hline 3 & $\begin{array}{l}\text { Penyusutan volumetric } \\
\text { (Volumetric shrinkage), \% }\end{array}$ & 12.64 (a) & 11.55 (a) & $\begin{array}{r}12.48 \\
\text { (a) }\end{array}$ & $\begin{array}{r}10.97 \\
\text { (a) }\end{array}$ & $\begin{array}{r}12.84 \\
\text { (a) }\end{array}$ \\
\hline 4 & $\begin{array}{l}\text { Penyusutan longitudinal } \\
\text { (Longitudinal shrinkage), \% }\end{array}$ & $\begin{array}{r}0.22 \\
\text { (a) }\end{array}$ & $\begin{array}{r}0.14 \\
\text { (a) }\end{array}$ & $\begin{array}{r}0.16 \\
\text { (a) }\end{array}$ & $\begin{array}{r}0.25 \\
\text { (a) }\end{array}$ & $\begin{array}{r}0.12 \\
\text { (a) }\end{array}$ \\
\hline 5 & $\begin{array}{l}\text { Penyusutan tangensial } \\
\text { (Tangential shrinkage), \% }\end{array}$ & $\begin{array}{r}6.74 \\
\text { (a) }\end{array}$ & $\begin{array}{r}6.47 \\
\text { (a) }\end{array}$ & $\begin{array}{r}7.55 \\
\text { (a) }\end{array}$ & $\begin{array}{r}4.35 \\
\text { (b) }\end{array}$ & $\begin{array}{r}7.91 \\
\text { (a) }\end{array}$ \\
\hline 6 & $\begin{array}{l}\text { Penyusutan radial } \\
\text { (Radial shrinkage), \% }\end{array}$ & $\begin{array}{r}4.21 \\
\text { (a) }\end{array}$ & $\begin{array}{r}3.62 \\
\text { (a) }\end{array}$ & $\begin{array}{r}4.32 \\
\text { (a) }\end{array}$ & $\begin{array}{r}3.32 \\
\text { (a) }\end{array}$ & $\begin{array}{r}4.08 \\
\text { (a) }\end{array}$ \\
\hline 7 & $\begin{array}{l}\text { Modulus elastisitas } \\
\text { (Modulus of elasticity), } \mathrm{kg} / \mathrm{cm}^{2}\end{array}$ & $\begin{array}{r}101.366 \\
\text { (a) }\end{array}$ & $\begin{array}{r}127.218 \\
\text { (a) }\end{array}$ & 103.099 (a) & $\begin{array}{r}122.360 \\
\text { (a) }\end{array}$ & $\begin{array}{r}117.417 \\
\text { (a) }\end{array}$ \\
\hline 8 & $\begin{array}{l}\text { Modulus patah } \\
\text { (Modulus of rupture), } \mathrm{kg} / \mathrm{cm}^{2}\end{array}$ & $\begin{array}{r}834 \\
\text { (a) }\end{array}$ & $\begin{array}{r}720 \\
\text { (b) }\end{array}$ & $\begin{array}{r}737 \\
\text { (a) }\end{array}$ & $\begin{array}{r}806 \\
\text { (b) }\end{array}$ & $\begin{array}{l}789 \\
(\mathrm{ab})\end{array}$ \\
\hline 9 & $\begin{array}{l}\text { Keteguhan tekan } \\
\text { (Compression strength), } \mathrm{kg} / \mathrm{cm}^{2}\end{array}$ & $\begin{array}{r}437.4 \\
\text { (a) }\end{array}$ & $\begin{array}{r}346.7 \\
\text { (b) }\end{array}$ & $\begin{array}{r}388.9 \\
\text { (a) }\end{array}$ & $\begin{array}{r}392.2 \\
\text { (a) }\end{array}$ & $\begin{array}{r}395.1 \\
\text { (a) }\end{array}$ \\
\hline 10 & $\begin{array}{l}\text { Keteguhan tarik } \\
\text { (Tensile strength), } \mathrm{kg} / \mathrm{cm}^{2}\end{array}$ & $\begin{array}{r}982 \\
\text { (a) }\end{array}$ & $\begin{array}{r}938 \\
\text { (a) }\end{array}$ & $\begin{array}{r}909 \\
\text { (a) }\end{array}$ & $\begin{array}{r}1017 \\
\text { (a) }\end{array}$ & $\begin{array}{r}952 \\
\text { (a) }\end{array}$ \\
\hline
\end{tabular}

Keterangan (Remarks):

1) Untuk setiap pohon (nomor 1 atau 2), merupakan rata-rata dari tingkat ketinggian pada batang pohon (For each tree (number 1 or 2), revealing the average from three height levels of the tree trunk)

2) Untuk setiap tingkat ketinggian pada batang pohon (pangkal, tengah atau ujung), merupakan rata-rata dari 2 pohon (nomor 1 dan 2) (For each height level on the tree trunk, e.g. bottom, center and top/ upperparts revealing the average from 2 trees (number 1 and 2))

3) Angka pada baris yang sama yang diikuti oleh huruf yang sama tidak berbeda nyata pada taraf 5\% (Figures in the same row followed by similar (common) letters are not significantly different at $5 \%$ level: $a>b$ )

\section{DAFTAR PUSTAKA}

Anonim. 1992. Manual Kehutanan. Departemen Kehutanan Republik Indonesia, Jakarta. Hlm.: 8-12.

Haygreen, J. G. dan Jim L. Bowyer. 1989. Hasil Hutan dan Ilmu Kayu. Suatu Pengantar. Gajah Mada Univercity Press. Yogyakarta. Hlm.: 274-350. 
Heyne, K. 1987. Tumbuhan Berguna Indonesia Jilid III. Badan Penelitian dan Pengembangan Kehutanan. Jakarta. Hlm.: 1117-1118.

Karnasudirdja, S. 1987. Pengetahuan Bahan Kayu. Sifat fisis dan mekanis. Departemen Kehutanan. Pusat Penelitian dan Pengembangan Hasil Hutan. Bogor.

Mandang, Y.I., I.K.N. Pandit. 1987. Seri Manual : Pedoman Identifikasi Jenis Kayu di Lapangan. PROSEA Network Office. Yayasan PROSEA Bogor. Hlm.: 101-102.

Martawijaya, A., I. Kartasujana, K.Kadir dan S.A. Prawira. 1981. Atlas Kayu Indonesia Jilid I. Balai Penelitian Hasil Hutan Bogor.

Tsoumis, G. 1991. Science and Technology of Wood. Structure, Properties, Utilization. Van Norstrand Reinhold. New York. P.111-180

Wardani, M., N. Hadjib, dan P. Sutigno. 2004. Jenis kayu andalan setempat. Surili. Volume 32 No.3/September 2004. Bandung. 